\title{
Protein Powder Derived Porous Carbon Materials as Supercapacitor Electrodes
}

\author{
Ben Niu ${ }^{1}$, Mengying Yuan ${ }^{1}$, Feng Jiang ${ }^{1}$, Mei Li $^{1,2,3, *}$ \\ ${ }^{1}$ School of Materials Science and Engineering, Qilu University of Technology (Shandong Academy of \\ Sciences), Jinan 250353, P.R. China \\ ${ }^{2}$ Shandong Provincial Key Laboratory of Processing and Testing Technology of Glass and Functional \\ Ceramics, Jinan 250353, P.R. China. \\ ${ }^{3}$ Key Laboratory of Amorphous and Polycrystalline Materials, Qilu University of Technology \\ (Shandong Academy of Sciences), Jinan 250353, P.R. China. \\ "E-mail: $\underline{\text { lim@qlu.edu.cn }}$
}

doi: $10.20964 / 2019.04 .33$

Received: 9 December 2018 / Accepted: 28 January 2019 / Published: 10 March 2019

\begin{abstract}
Protein-based microporous carbon (PMC) with high nitrogen, sulfur content and the specific surface area was obtained from commercial protein powder ( $\mathrm{PP}$ ) by $\mathrm{KOH}$ activation. Many interconnected micropores and mesopores were formed in the carbonization process, the specific surface area of the PMC was up to $1117 \mathrm{~m}^{2} \mathrm{~g}^{-1}$. The nitrogen content is 15.29 at.\%, sulfur percent is 0.71 at.\% in the asprepared PMC. Both high specific area and heteroatom content bring the ideal capacitance characteristics when PMC was fabricated as supercapacitor electrodes. The different carbonization temperature and activation ratio of $\mathrm{PP}$ to $\mathrm{KOH}$ have been discussed to get the best electrochemical performances. The specific capacitance of PMC600-1:2 was up to $336 \mathrm{~F} \mathrm{~g}^{-1}$ at a current density of $1 \mathrm{~A} \mathrm{~g}^{-1}$, much higher than that of commercial electrodes. The capacitance retention is $173 \mathrm{~F} \mathrm{~g}^{-1}$ at $10 \mathrm{~A} \mathrm{~g}^{-1}$, indicating that the PMC owns good rate capability. At the same time, the cycling stability of the sample is $83 \%$ after 10000 cycles at $10 \mathrm{~A} \mathrm{~g}^{-1}$. Furthermore, an as-fabricated PMC-based symmetric supercapacitor device shows a high energy density of $27 \mathrm{~W} \mathrm{~h} \mathrm{~kg}^{-1}$ at a power density of $900 \mathrm{~W} \mathrm{~kg}^{-1}$.
\end{abstract}

Keywords: Microporous carbon, Nitrogen doping, Electrochemical performance, Supercapacitors

\section{FULL TEXT}

(C) 2019 The Authors. Published by ESG (www.electrochemsci.org). This article is an open access article distributed under the terms and conditions of the Creative Commons Attribution license (http://creativecommons.org/licenses/by/4.0/). 